\title{
Investigation of the Effect of Drill Bit Feature on Hole Surface Quality and Tool Wear
}

\author{
Murat KIYAK* \\ Yildiz Technical University,Department of Mechanical Engineering, İstanbul \\ kiyak@yildiz.edu.tr, ORCID: 0000-0002-9906-8683, Phone: (0212) 3832801
}

\begin{tabular}{|c|c|}
\hline ARTICLE INFO & ABSTRACT \\
\hline Article history: & Drilling operations have an important role in manufacturing industries and the application range is about \\
\hline & $\begin{array}{l}33 \% \text { among the machining methods. In drilling processes, hole quality is affected by workpiece material, } \\
\text { drilling parameters, drill diameter, drill bit features. }\end{array}$ \\
\hline $\begin{array}{l}\text { Received } 14 \text { July } 2021 \\
\text { Received in revised form } 10\end{array}$ & In this study, the surface quality of the hole and the drill bit wear were investigated experimentally when \\
\hline September 2021 & drilling AISI 1040 steel and A17075 aluminum workpieces with twist drills. Three different types of twist \\
\hline Accepted 20 September 2021 & drill bits (polished, rolled and TiN coated) with diameters of $8 \mathrm{~mm}$ and $10 \mathrm{~mm}$ were used for drilling. \\
\hline Available online 28 September 2021 & Hole surface roughness was investigated at the hole entry and hole exit. While revealing the surface \\
\hline Keywords: & $\begin{array}{l}\text { quality change at the hole entry-exit, the effect of the drill feature difference on the surface quality has } \\
\text { been tried to be determined. In general, hole surface quality decreased with increasing drill bit diameter }\end{array}$ \\
\hline $\begin{array}{l}\text { Twist drill bits, hole surface } \\
\text { roughness, tool wear }\end{array}$ & $\begin{array}{l}\text { when drilling both materials. The lowest surface roughness values were obtained in the use of TiN } \\
\text { coated drill bits. Drill bit wear was also measured in the study, and it was seen that the drill bit wear } \\
\text { increased with increasing drill bit diameter. The least drill bit wear value was also observed in TiN } \\
\text { coated drill bits. }\end{array}$ \\
\hline
\end{tabular}

Doi: $10.24012 /$ dumf.1002180

* Corresponding author

\section{Introduction}

Today, in the manufacturing industry, although the manufacturing methods are quite advanced, the drilling method is still one of the most widely used machining methods, and its application rate is about $33 \%$ among all machining methods. The most important parameters in drilling are cutting speed and feed. These parameters directly affect the cutting temperature, cutting forces, tool wear, hole surface quality and hole geometry. Hole surface quality is an important factor for machine parts to operate at the desired efficiency. In drilling, chip control is difficult due to the formation of swarf inside the hole, which affects the cutting forces, cutting temperature and therefore the quality of the drilled hole. In the drilling process, in addition to the surface roughness, there are situations that affect the hole quality such as burr formation at the hole exit, circularity and offset in the hole axis. Hole quality also depends on various conditions such as cutting speed, feed, drill bit geometry and material, drill bit manufacturing characteristics, and workpiece material. Drill geometry, material and the technological properties of the drill bit have a significant impact on hole surface quality. Along with these factors affecting the surface quality, drilling parameters and the resistance of the workpiece to machining will cause tool wear.

In this study, $20 \mathrm{~mm}$ thick workpieces made of AISI 1040 steel and Al 7075 aluminum alloy materials, which are widely used in the manufacturing industry, were drilled with HSS drill bits produced with three different technologies (rolled, polished, TiN coated). Drill bits with diameters of $8 \mathrm{~mm}$ and $10 \mathrm{~mm}$ were used in the study. Hole surface roughness at the hole entry and hole exit were examined, while revealing the surface quality change at the entry-exit, it was tried to determine the effect of the drill feature difference on the surface quality. The literature research conducted within the scope of these topics examined in the study is given in detail below.

\section{Literature Review}

The literature review on the subject was made in two groups, especially on the drilling of workpieces from steel and aluminum materials, based on the studies carried out in the last ten years. The research focused especially on hole surface quality and tool wear. Marui et al. [1] stated that with increasing cutting speed, generally better hole surface quality is obtained, but high cutting speeds negatively affect hole cylindricality. Kilıçkap et al. [2] 
carried out experimental studies in the drilling of AISI 1040 steel material with $8 \mathrm{~mm}$ diameter TiN coated HSS drill bit, under MQL, compressed air and dry chip removal conditions. In the study, they chose the cutting speed in the range of $5-15 \mathrm{~m} / \mathrm{min}$ and the feed in the range of $0.1-0.3$ $\mathrm{mm} / \mathrm{rev}$. For the same feed rate, they determined that when the cutting speed is increased three times, the surface roughness of the hole increases-deteriorates by about $55 \%$. It was found that the surface roughness increased with the increase of feed rate, depending on the cutting speed. Garg et al. [3] selected a feed of 0.01-0.02 mm/rev and a cutting speed of $12 \mathrm{~m} / \mathrm{min}-37 \mathrm{~m} / \mathrm{min}$ in the drilling of AISI H11 steel material at a depth of 10 and $20 \mathrm{~mm}$ using $10 \mathrm{~mm}$ diameter TiAlN coated carbide drills. They observed that the hole surface roughness increased by $43 \%$ when the feed rate was doubled. They also observed that the hole surface roughness increased by $70 \%$ when the hole depth was doubled from $10 \mathrm{~mm}$ to $20 \mathrm{~mm}$. Ankalaki et al. [4], in their study, stated that the surface roughness decreases with the increase of cutting speed and stated that the basic condition of reducing the production cost and improving the quality by minimizing the errors in any manufacturing industry is to determine the appropriate working parameters. Naemah et al. [5] studied the drilling of Fe360B steel material with HSS drill bits with diameters of $10 \mathrm{~mm}$ and $12 \mathrm{~mm}$, with different drill bit angles between 900 and 1400 . They applied the cutting speed as $30 \mathrm{~m} / \mathrm{min}$ and the feed in the range of $0.1-0.3 \mathrm{~mm} / \mathrm{rev}$. In the study, it was revealed that the surface roughness decreased with the increase of the spindle speed (cutting speed) and the drill bit angle, and the surface roughness increased with the increase of the drill diameter. Kamdani et al. [6] studied the drilling of $316 \mathrm{~L}$ steel material with an $8 \mathrm{~mm}$ diameter uncoated carbide drill bit for $15 \mathrm{~mm}$. Cutting speed $41 \mathrm{~m} / \mathrm{min}$, feed $0.10-0.15 \mathrm{~mm} / \mathrm{rev}$. It was observed that the surface roughness increased by about $30 \%$ with an increase of $50 \%$ in the feed rate. Krivokapić et al. [7] studied the drilling of $42 \mathrm{CrMo} 4$ steel material with $3 \mathrm{~mm}, 5 \mathrm{~mm}$ and $8 \mathrm{~mm}$ diameter HSS drill bits. They applied the cutting speed as $20 \mathrm{~m} / \mathrm{min}$ and the feed as 0.03 , 0.05 and $0.10 \mathrm{~mm} / \mathrm{rev}$. Drilling depths were chosen as 9 $\mathrm{mm}, 15 \mathrm{~mm}, 24 \mathrm{~mm}, 3$ times the drill diameters. At the same cutting speed, the roughness increased as the feed rate increased. They stated that the surface roughness increased at the hole exit under all experimental conditions. Wegert et al. [8] examined the temperature and wear in the drilling zone. They stated that with a drill bit, the temperature value increased to $150^{\circ} \mathrm{C}$ after three dry drilling operations. It was also noted that the outer edge of the cutting tool had higher wear. Sharif et al. [9] performed $10 \mathrm{~mm}$ drilling of $316 \mathrm{~L}$ steel material with a 4 $\mathrm{mm}$ diameter uncoated carbide drill bit, and investigated the tool wear and hole surface quality. They chose the cutting speed as $18 \mathrm{~m} / \mathrm{min}$ and $25 \mathrm{~m} / \mathrm{min}$, and the feed in the range of $0.03-0.06 \mathrm{~mm} / \mathrm{rev}$. They reached the reference wear value of $0.3 \mathrm{~mm}$ at the end of 20 holes at a cutting speed of $18 \mathrm{~m} / \mathrm{min}$ at $0.03 \mathrm{~mm} / \mathrm{rev}$ feed and at the end of 7 holes at a cutting speed of $25 \mathrm{~m} / \mathrm{min}$ at $0.06 \mathrm{~mm} / \mathrm{rev}$ feed. They observed that tool life decreases as cutting speed and/or feed increases. In addition, they stated that when the cutting speed increased by $38 \%$, the surface roughness values of the holes decreased by approximately $23 \%$ and better surface quality was achieved. Jindal [10] used HSS drill bits in the diameter range of $5-12 \mathrm{~mm}$ for drilling mild steel materials. He chose the cutting speed in the range of $8 \mathrm{~m} / \mathrm{min}$ to $22 \mathrm{~m} / \mathrm{min}$ and the feed in the range of $0.11-0.14 \mathrm{~mm} / \mathrm{rev}$. In these selected working conditions, the minimum $(30 \mu \mathrm{m})$ wear value at the lowest cutting speed and the maximum $(190 \mu \mathrm{m})$ wear value at the highest cutting speed were determined. Akıncıoglu et al. [11] drilled $7 \mathrm{~mm}$ thick AISI D2 steel using $5 \mathrm{~mm}$ diameter uncoated carbide, TiN coated carbide and TiAlN coated carbide drill bits. They chose the cutting speed in the range of $50-65 \mathrm{~m} / \mathrm{min}$ and the feed as $0.0063 \mathrm{~mm} / \mathrm{rev}$ and $0.08 \mathrm{~mm} / \mathrm{rev}$. At the same drilling conditions, the TiNcoated drill bit produced approximately $23 \%$ better surface quality than the uncoated drill bit. They stated that while the uncoated drill bit creates higher surface roughness, the increase in feed causes an increase in the surface roughness, and the coated drill bit provides 3 times better tool life than the uncoated drill bit. Saleem et al. [12] applied drilling to $104 \mathrm{~mm}$ thick AISI 1045 steel material with an $8 \mathrm{~mm}$ diameter uncoated HSS drill bit, with $3 \mathrm{~mm}$ and $5 \mathrm{~mm}$ steps. In the study, the cutting speeds were chosen as $6 \mathrm{~m} / \mathrm{min}$ and $15 \mathrm{~m} / \mathrm{min}$, and the feed rate as 10 $\mathrm{mm} / \mathrm{min}, 15 \mathrm{~mm} / \mathrm{min}, 20 \mathrm{~mm} / \mathrm{min}$. Surface roughness was measured at the hole entrance and exit, and it was stated that higher surface roughness occurred at the hole exit under all conditions. It has been stated that the determined wear values are formed as steep curves for the first $100 \mu \mathrm{m}$ due to the rapid initial wear. Nouari et al. [13] applied 25 $\mathrm{m} / \mathrm{min}$ cutting speed and $0.04 \mathrm{~mm} / \mathrm{rev}$ feed in their study on drilling AA 2024 aluminum material with $6 \mathrm{~mm}$ diameter uncoated HSS drill bit. They stated that the surface roughness increased by $25 \%$ in the creation of three holes at the drilling depth determined as $8 \mathrm{~mm}$, compared to the case of drilling a single hole. They stated that the increase in surface roughness was caused by tool wear. In addition, they stated that HSS drills are not suitable for dry drilling of aluminum alloys, regardless of the cutting speed used. Haq et al. [14] studied the drilling of LM 25 aluminum material with a TiN-coated $10 \mathrm{~mm}$ HSS drill bit at different tool tip angles. The cutting speed was selected in the range of $35 \mathrm{~m} / \mathrm{min}$ to $88 \mathrm{~m} / \mathrm{min}$, the feed in the range $0.050 \mathrm{~mm} / \mathrm{rev}$ to $0.200 \mathrm{~mm} / \mathrm{rev}$. The hole depth is $20 \mathrm{~mm}$. In the study, the surface roughness was measured between $2.22 \mu \mathrm{m}$ and $8.27 \mu \mathrm{m}$. Kurt et al. [15] drilled Al 2024 aluminum with $10 \mathrm{~mm}$ diameter uncoated HSS, TiN coated HSS and TiAlN coated HSS drill bits. They chose the cutting speed between $30 \mathrm{~m} / \mathrm{min}$ and 60 $\mathrm{m} / \mathrm{min}$, and the feed between $0.15 \mathrm{~mm} / \mathrm{rev}$ and 0.25 $\mathrm{mm} / \mathrm{rev}$. The hole surface roughness determined under these test conditions are between $3.95 \mu \mathrm{m}$ and $7.90 \mu \mathrm{m}$. Giasin et al. [16] studied Al 2024 aluminum drilling with a $6 \mathrm{~mm}$ diameter drill bit at different cutting speeds and different feed rates. They stated that surface roughness increased with increasing spindle speed and feed rate, and the effect of feed rate on surface roughness was greater than spindle speed. Sreenivasulu et al. [17] optimized the surface roughness and circularity deviation of drilled holes 
in different aluminum materials $(2014,6069,6061,7075)$ especially used in the automotive and aerospace industries. Experimental studies were carried out with drill bits of different diameters and tip angles, at different cutting speeds and different feed rates. Surface roughness values ranging from $0.15 \mu \mathrm{m}$ to $0.56 \mu \mathrm{m}$ were determined. Elajrami et al. [18], in their study on drilling Al 2024 aluminum material using HSS drill bit, the cutting speed was chosen between $15 \mathrm{~m} / \mathrm{min}$ and $22 \mathrm{~m} / \mathrm{min}$, and the feed was between $0.3 \mathrm{~mm} / \mathrm{rev}$ and $0.8 \mathrm{~mm} / \mathrm{rev}$. They stated that there was a $166 \%$ difference between the selected parameters and the lowest and highest surface roughness values obtained. Ficici et al. [19], in their study on drilling Al 7075 aluminum material at $20 \mathrm{~mm}$ and $30 \mathrm{~mm}$ depth by using HSS and TiN coated HSS drill bits, found that the cutting speed was between $15 \mathrm{~m} / \mathrm{min}$ and $25 \mathrm{~m} / \mathrm{min}$, the feed was $0.05 \mathrm{~mm} / \mathrm{rev}$ It was selected in the range of 0.15 $\mathrm{mm} / \mathrm{rev}$. With the selected parameters, the smallest surface roughness value obtained was $1.00 \mu \mathrm{m}$, the highest surface roughness value was $3.00 \mu \mathrm{m}$.

The manufacturing industry focuses on producing high quality products at minimum cost. In this respect, the results of the literature review are given above in detail and quantitatively, so that tool selection and parameter determination can be made, depending on the expectations, in order to find answers to possible demands in the relevant manufacturing areas. In addition, within the scope of the subject, the results of the literature for the targeted studies are given below qualitatively. It is stated that in steel workpieces, under the same drilling conditions, TiN coated drill bits give good results and the surface quality of holes created by carbide drill bits is better than holes created with high speed steel drill bits. In the drilling of aluminum alloy workpieces, it has been observed that the cutting speed does not affect the hole surface roughness at low feed rate, but the surface roughness decreases as the cutting speed increases, and the surface roughness increases as the feed increases. In the literature, it is seen that as the feed rate increases, the surface roughness increases and tool wear also affects the surface roughness. It can be noted that the new drill bit reduces the surface roughness compared to the worn drill bit. In all studies, high cutting speed and low feed generally appear to result in better hole surface quality.

In this study, the effects of spiral drill bits with different properties on hole surface roughness and drill bit wear were experimentally investigated on two different workpiece materials, which are widely used in the manufacturing industry.

\section{Material and Methods}

Drilling processes were carried out in FIRST brand MCV300 model CNC machining center. The experiments were carried out under dry cutting conditions. In Figure 1, experimental studies and experimental design are given schematically.

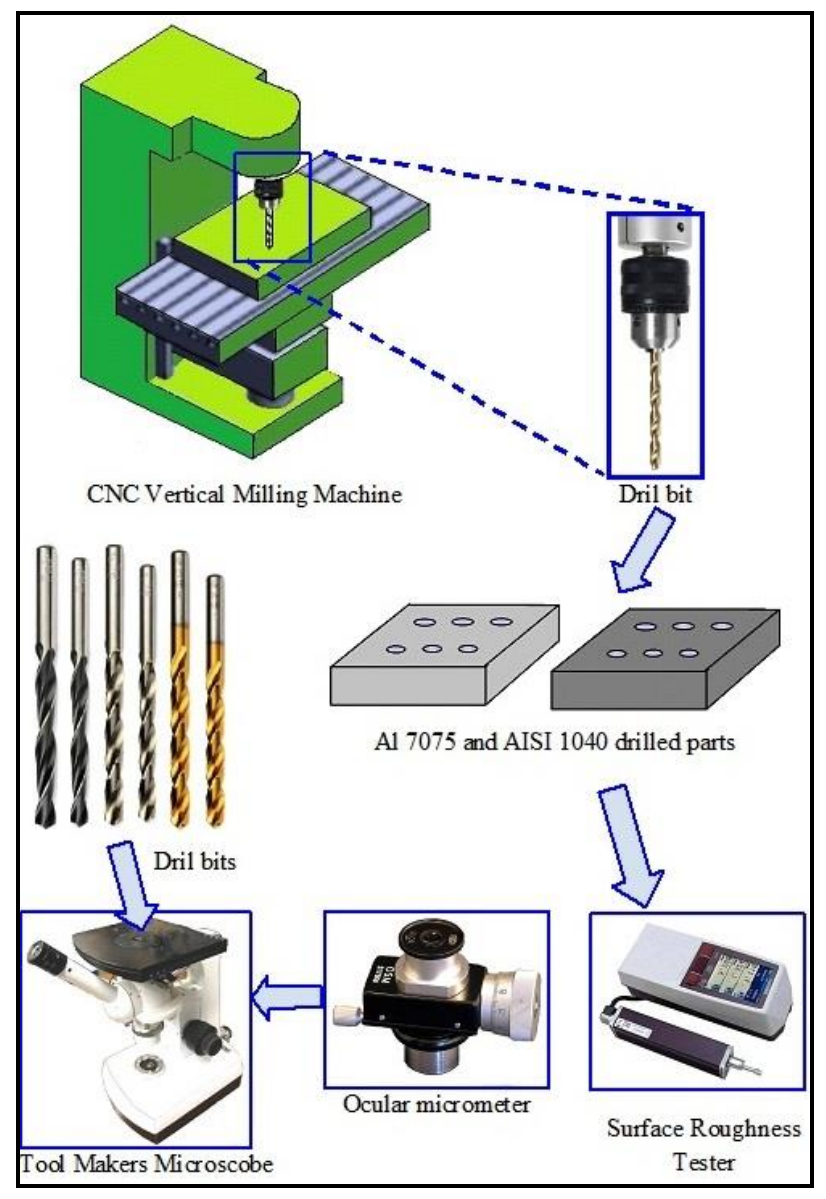

Figure 1. Experimental design and setup

Three different HSS spiral drill bits with $8 \mathrm{~mm}$ and $10 \mathrm{~mm}$ diameters, rolled, polished and TiN coated were used. The general specifications of the drill bits are given in Table 1.

Table 1. Properties of HSS spiral drill bits used in experiments.

\begin{tabular}{cc}
\hline Drill type & Properties and views of drill bits \\
DIN338 & ISO 235, \\
Rolled & $\mathrm{N}$ type $118^{\circ}$ \\
$(8-10 \mathrm{~mm})$ & \\
DIN338 & ISO 235, \\
Polished & $\mathrm{N}$ type $118^{\circ}$ \\
$(8-10 \mathrm{~mm})$ & \\
DIN338 & ISO 235, \\
TiN Coated & $\mathrm{N}$ type:135 \\
$(8-10 \mathrm{~mm})$ &
\end{tabular}

In the selection of workpiece materials, their widespread use in the manufacturing industry was taken into account, and the drilling parameters were determined by considering the relevant literature and application principles. 
The chemical composition and mechanical properties of AISI 1040 steel and Al 7075 used in the experiments are given in Table 2 and Table 3. Al 7075 aluminum alloy is preferred in the aerospace industry, but its machining is more difficult than other aluminum alloys due to its high strength.

Table 2. Chemical composition and mechanical properties of AISI 1040 steel

\begin{tabular}{ccccc}
\hline$\% \mathrm{C}$ & $\% \mathrm{Fe}$ & $\% \mathrm{Mn}$ & $\% \mathrm{P}$ & $\% \mathrm{~S}$ \\
\hline $0.37-0.4$ & $98.6-99.0$ & $0.60-0.90$ & $<0.04$ & $<0.05$ \\
\hline \multirow{2}{*}{ Hardness } & Tensile & Tensile & Shear \\
$(\mathrm{HV})$ & Strength & Strength & Modulus \\
& Ultimate & Yield & $(\mathrm{GPa})$ \\
\hline 155 & $525(\mathrm{MPa})$ & $290(\mathrm{MPa})$ & 80 \\
\hline
\end{tabular}

Table 3. Chemical composition and mechanical properties of Al 7075 Aluminum alloy

\begin{tabular}{rccccc}
\hline $\mathrm{Al} \%$ & $\mathrm{Cr} \%$ & $\mathrm{Cu} \%$ & $\mathrm{Mg} \%$ & $\mathrm{Mn} \%$ & $\mathrm{Zn} \%$ \\
\hline $87-91$ & $0.18-0.2$ & $1.2-2$ & $2,1-2,9$ & 0,30 & $5,1-6,1$ \\
\hline \multirow{4}{*}{ Up to } & Tensile & Tensile & \\
$100 \mathrm{~mm}$ & Strength & Strength & Hardness \\
\cline { 2 - 5 } & Ultimate & Yield & \\
\cline { 2 - 5 } & $533(\mathrm{MPa})$ & $462(\mathrm{MPa})$ & $150(\mathrm{HB})$ \\
\hline
\end{tabular}

The feed rate was taken as $0.1 \mathrm{~mm} / \mathrm{rev}$, taking into account the drill bit specifications and the relevant literature [2, 5, $10,12,13,15,18,19]$. The cutting speeds determined according to the material of the workpieces are given in Table 4.

Table 4. Cutting speeds according to drill bit properties and diameter

\begin{tabular}{cccc}
\hline & \multirow{2}{*}{$\begin{array}{c}\text { Diameter } \\
\text { of drill }(\mathrm{mm})\end{array}$} & \multicolumn{2}{c}{ Cutting speed (m/min) } \\
\cline { 2 - 4 } & 8 & AISI1040 & Al7075 \\
\hline DIN 338 & 10 & 32 & 38 \\
Rolled & 8 & 32 & 47 \\
\hline DIN 338 & 10 & 32 & 38 \\
Polished & 8 & 40 & 47 \\
\hline DIN 338 & 10 & 40 & 38 \\
\cline { 2 - 4 } TiN Coated & & & 47 \\
\hline
\end{tabular}

\section{Experimental Results and Discussion}

\section{Surface quality of the hole}

In the experiments, $20 \mathrm{~mm}$ thick workpieces were drilled through. Experiments were repeated three times, using a new drill bit in each experiment. Mitutoyo brand SJ-210R model surface roughness tester was used to measure the Arithmetic Average Roughness ( $\mathrm{Ra}$ ) values. Hole surface roughness was measured from both the hole entrance and hole exit to determine the effects of drilling parameters and tool wear. The measurements at the entry were measured $5 \mathrm{~mm}$ after the drill entry surface, and the measurements on the exit side were measured $5 \mathrm{~mm}$ before the drill exit surface. Surface roughness measurements were measured from $90^{\circ}$ different points both at the inlet and at the exit, and the average values were taken. Depending on the drill diameter and the workpiece material, the surface roughness values obtained using rolled, polished, TiN coated HSS spiral drill bits are graphically shown in Figure 2 and Figure 3. In Figure 2, the values obtained when drilling the steel workpiece are given, and it is seen that drilling with TiN coated HSS drills in both $8 \mathrm{~mm}$ diameter and $10 \mathrm{~mm}$ diameter gives much better results in terms of surface roughness at hole entry and exit. Figure 2 shows that TiN coated drill bits contribute positively not only to wear resistance but also to surface roughness. It can be stated that this is due to the low friction coefficient of the coating material, which facilitates the chip flow and positively affects the surface roughness. In drilling AISI 1040 steel, the surface roughness of the hole exit increased with increasing drill diameter for all drill bit types.

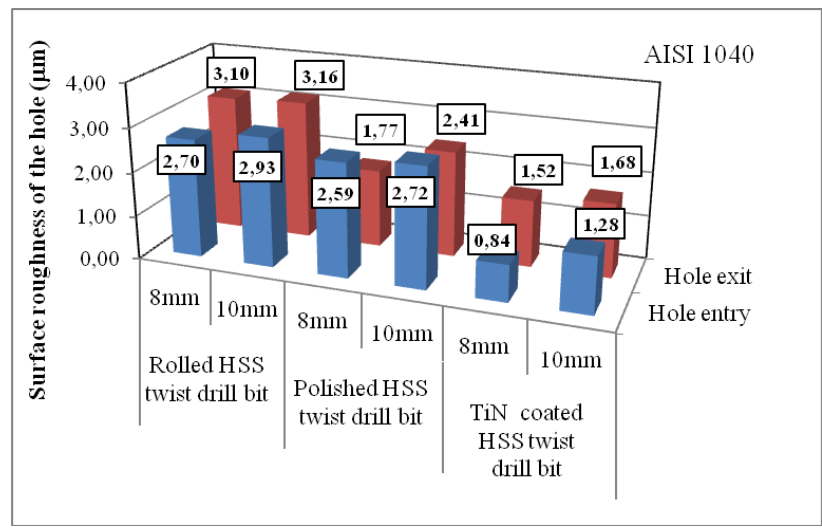

Figure 2. Hole surface roughness measured in AISI 1040 steel workpiece

As seen in Figure 3, the lowest surface roughness was observed with the TiN coated drill bit at the hole entry and hole exit for both drill diameters when drilling Al7075 aluminum alloy material.

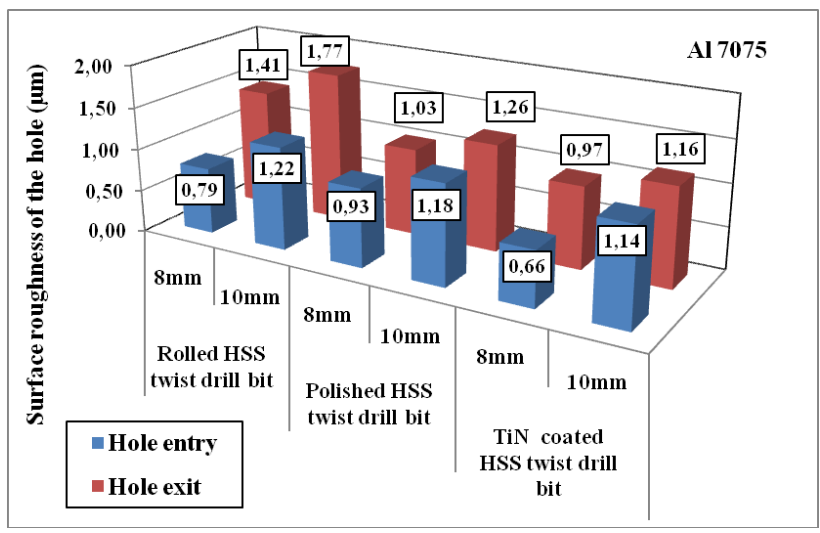

Figure 3. Hole surface roughness measured in Al 7075 aluminum alloy workpiece

In the literature [5], it is stated that the surface roughness increases as the drill diameter increases. The values obtained as a result of the study are quite compatible with 
the relevant literature. In addition, in the literature [7, 12], it is stated that there is more surface roughness at the hole exit under all experimental conditions. In this respect, the results are in line with the literature. In the literature [12], it is stated that the surface roughness is $35-50 \%$ lower at the hole entry compared to the hole exit, and the surface quality is worse at the exit. Due to the friction of the chip in the hole and the wear of the tool, the surface quality is relatively poor at the exit part of the hole. It has been observed that TiN coated HSS drill bit provides better surface roughness than uncoated HSS drill bits. This situation is quite compatible with the relevant literature [11].

\section{Drill bit wear}

SOIF brand microscope and OSM brand ocular micrometer with $0.1 \mu \mathrm{m}$ precision were used to measure the wear values of drill bits. The measurement of the average width of the wear area was made according to the ISO 1993:3685 standard. The wear images of drilling Al 7075 material with $10 \mathrm{~mm}$ diameter drill bits with different features are given in Figure 4.

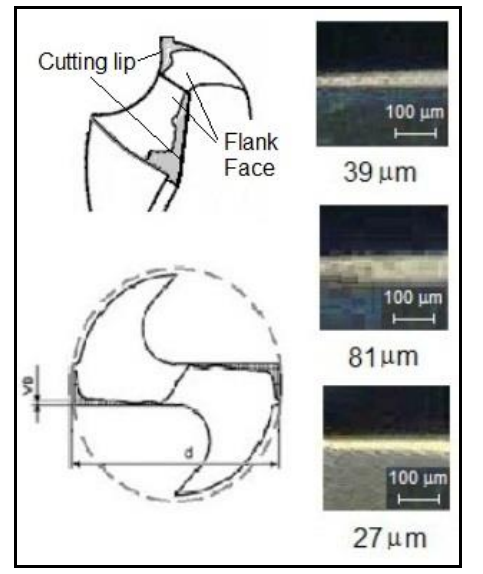

Figure 4. Wear images of drill bits with different properties

The wear values of the drill bits are given in Figure 5. The following evaluation has been reached in the drilling of both materials used in the experiments and whose hardness values are close to each other.

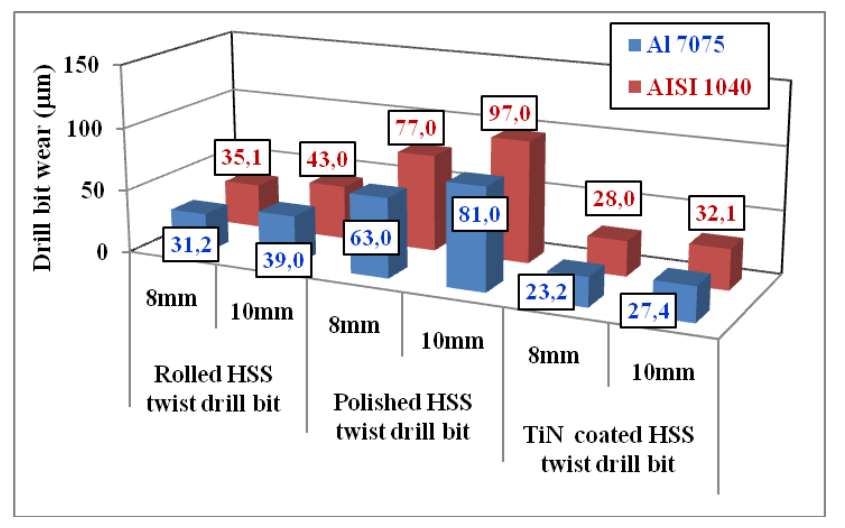

Figure 5. Wear of drill bits
Minimum wear was determined when drilling the aluminum workpiece with a TiN coated drill bit. TiN coating increases the wear resistance of the drill bit. The wear values occurring in drill bits with different properties and different diameters are seen in TiN coated, rolled and polished drill bits, respectively. In the study of drilling AISI 1045 steel with an $8 \mathrm{~mm}$ diameter HSS drill bit, it has been stated in the literature[12] that the determined wear values occur as steep curves for the first $100 \mu \mathrm{m}$ due to the rapid initial wear. The reason for the highest wear value observed in ground HSS drill bits is thought to be due to the rapid wear of the cutting edges in the rapid initial wear zone [12]. In the study, it is seen that the determined wear values are compatible with the relevant literature. Akıncıoğlu [11] stated that the coated drill bit provides 3 times better tool life than the uncoated drill bit. Since the hardness of the Al 7075 material is close to the hardness of the AISI 1040 material, it caused tool wear as much as the tool wear in the machining of mild steel, since its machinability is not very good due to its hardness. In the literature [10], for drilling mild steel with HSS drill, wear values of $30 \mu \mathrm{m}$ in $5 \mathrm{~mm}$ drill bit and $190 \mu \mathrm{m}$ in 12 $\mathrm{mm}$ drill bit were measured. Increasing drill diameter also affects tool wear. It was observed that the drill bit wear values increased with the increase of the drill bit diameter. It is seen that the measured wear values are in good agreement with the literature [10]. Experimental results showed that drill bit wear increased with increasing drill bit diameter

Depending on the tool wear, the volume of metal removed per unit wear was determined and given in Figure 6. When the wear graph (Figure 5) is examined, it is seen that more wear values are measured in large diameter drills, which is in line with the relevant literature. However, when the wear values are proportioned considering the hole volumes, it is seen that the chip volume removed by the large diameter drill bits is higher. The wear values per unit chip volume removed are given in Figure 5. It is observed that large diameter drill bits have less wear per $\mathrm{cm}^{3}$ of removed volume for each drill bit specification and material type. This graph, which can be an important selection criterion for hole cost, can be evaluated together with current drill costs and can provide an approximation in terms of possible tool life based on material removal rate.

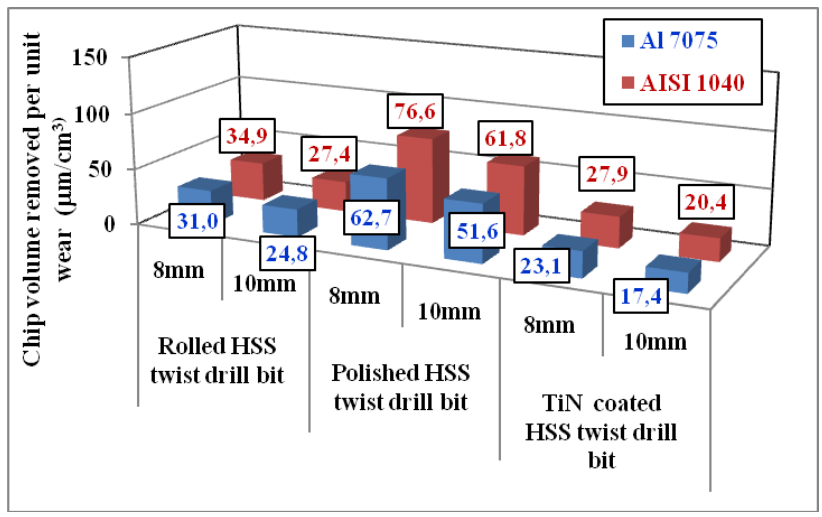

Figure 6. Removed chip volume per unit wear value 
In Figure 6, lower values mean better results. In this regard, coated HSS drill bits appear to perform quite well in drilling both materials.

\section{Conclusion}

In this study, the effects of drill bit properties on wear of drill bits and surface roughness at hole entry and hole exit were investigated when drilling different workpiece materials.

- In general, hole surface quality decreased with increasing drill bit diameter when drilling both materials. When drilling AISI 1040 material with 8 $\mathrm{mm}$ drill bits, TiN-coated drill bits provided 59.3\% better surface quality than rolled drill bits and $46 \%$ better than polished drill bits. In the case of drilling with a $10 \mathrm{~mm}$ drill bit, TiN-coated drill bits provided $51.3 \%$ better surface quality than rolled drill bits and $42.27 \%$ better than polished drill bits. When Al 7075 material is drilled with an $8 \mathrm{~mm}$ drill bit, TiN coated drill bits provide $25.9 \%$ better surface quality than rolled drill bits and $17.3 \%$ better than polished drill bits. In the case of drilling with a $10 \mathrm{~mm}$ drill bit, TiNcoated drill bits provided $22.9 \%$ better surface quality than rolled drill bits and $5.65 \%$ better than polished drill bits.

- It is seen that $8 \mathrm{~mm}$ TiN coated drill bit wears $25.64 \%$ less than the rolled drill bit and $63.17 \%$ less than the polished drill bit when drilling Al 7075 material. It is seen that the $10 \mathrm{~mm}$ TiN coated drill bit wears $29.74 \%$ less than the rolled drill bit and $66.17 \%$ less than the polished drill bit. When drilling AISI 1040 material, it is seen that the $8 \mathrm{~mm}$ TiN coated drill bit wears $20.23 \%$ less than the rolled drill bit and $63.64 \%$ less than the polished drill bit. It is seen that the $10 \mathrm{~mm}$ TiN coated drill bit wears $25.35 \%$ less than the rolled drill bit and $66.91 \%$ less than the polished drill bit.

- The preferred drill bit type, such as rolled, polished or TiN coated, is an important criterion for hole cost. Considering the wear value depending on the chip volume removed, an approximation can be provided for the probable tool life and drill cost. In the experimental studies carried out with selected parameters, it was observed that the minimum surface roughness was achieved with TiN coated HSS drills and the minimum tool wear occurred in TiN coated HSS drills when drilling both materials. TiN coated HSS drills provide advantages in terms of manufacturing costs due to their low wear values and use at high cutting speeds. However, it should not be overlooked that TiN coated HSS spiral drill bits can have negative results in continuous use when drilling Al materials due to the reaction of the coating with the workpiece material.

\section{Ethics committee approval and conflict of interest statement}

There is no need to obtain permission from the ethics committee for the article prepared.

There is no conflict of interest with any person / institution in the article prepared.

\section{References}

[1] H. Endo, T. Murahashi and E. Marui, "Accuracy estimation of drilled holes with small diameter and influence of drill parameter on the machining accuracy when drilling in mild steel sheet", Int. J. of Mach. Tools \& Manuf., vol. 47, pp. 125-181, 2007, https://doi.org/10.1016/j.ijmachtools.2006.02.001

[2] E. Kilickap, M. Huseyinoglu and A. Yardimeden, "Optimization of drilling parameters on surface roughness in drilling of AISI1045 using response surface methodology and genetic algorithm", Int. J. Adv. Manuf. Tech., vol. 52, pp. 79-88, 2011, https://doi.org/10.1007/s00170-010-2710-7

[3] S. Garg, G.K. Goyal, “A study of surface roughness in drilling of AISI H11 die steel using face centered design", IJIRST Int. J. for Innovative Research in Sci.\&Tech. vol. 1, no. 12, pp.464-474, 2015, ISSN: 2349-6010

[4] S. Ankalagi, V.N. Gaitonde and P. Petkar, "Experimental Studies on Hole Quality in Drilling of AS182 Steel”, Materials Today:Proceedings, vol. 4, no. $10,11201-11209,2017$, ISSN 2214-7853 https://doi.org/10.1016/j.matpr.2017.09.041

[5] I.M. Naemah, K.N. Abed and A.A. Shehab, "Investigation the effect of cutting parameters on surface roughness in drilling operation of steel Fe360.B, $2^{\text {nd }}$ Int. Symp. on Multidisciplinary Studies and Innovative Tech.(ISMSIT), pp. 1-5, 2018, https://doi.org/10.1109/ISMSIT.2018.8567056

[6] K. Kamdani et al., "Study of cutting force and surface roughness on drilling stainless steel 316 L under various coolant condition", Key Engineering Materials, vol. 791, pp. 117-122, 2018, https://doi.org/10.4028/www.scientific.net/kem.791.1 $\underline{16}$

[7] Z. Krivokapić et al., "Modelling surface roughness in the function of torque when drilling", Metals, vol. 10, no. 3, pp. 337, 2020, https://doi.org/10.3390/met10030337

[8] R. Wegert et al., "Temperature monitoring in the subsurface during single lip deep hole drilling", Techn. Messen, vol. 87, no. 12, pp. 757-767, 2020, https://doi.org/10.1515/teme-2020-0055

[9] A.Z. Sultan, S. Sharif and D. Kurniawan, "Effect of machining parameters on tool wear and hole quality of AISI 316L stainless steel in conventional drilling”, 
Procedia Manufacturing, vol. 2, pp. 202-207, 2015, https://doi.org/10.1016/j.promfg.2015.07.035

[10] A. Jindal, "Analysis of tool wear rate in drilling operation using scanning electron microscope (SEM)", J. of Minerals \& Materials Characterization \& Engineering, vol. 11, no. 1, pp. 43-54, 2012, https://www.scirp.org/pdf/jmmce20120100004_99370 832.pdf

[11] S. Akıncioğlu et al.. "ANN-based prediction of surface and hole quality in drilling of AISI D2 cold work tool steel", Int. J. Adv. Manuf. Technol. vol. 68, pp.197-207, 2013, https://doi.org/10.1007/s00170$\underline{012-4719-6}$

[12] S. Khan et al., "Deep hole drilling of AISI 1045 via high-speed steel twist drills: evaluation of tool wear and hole quality", Int. J. Adv. Manuf. Technol. vol. 93, pp. 1115-1125, 2017, https://doi.org/10.1007/s00170$\underline{017-0587-4}$

[13] M. Nouari et al., "Effect of machining parameters and coating on wear mechanisms in dry drilling of aluminium alloys", Int. J. of Machine Tools and Manuf., vol. 45, no. 12-13, pp. 1436-1442, 2005, https://doi.org/10.1016/j.ijmachtools.2005.01.026

[14] A.N. Haq, P. Marimuthu, and R. Jeyapaul, "Multi response optimization of machining parameters of drilling $\mathrm{Al} / \mathrm{SiC}$ metal matrix composite using grey relational analysis in the Taguchi method", Int. J. Adv. Manuf. Tech., vol. 37, pp.250-255, 2008, https://doi.org/10.1007/s00170-007-0981-4
[15] M. Kurt, E. Bagci and Y. Kaynak, "Application of Taguchi methods in the optimization of cutting parameters for surface finish and hole diameter accuracy in dry drilling processes", Int. J. $A d v$. Manuf. Technol. vol. 40, pp. 458-469, 2009, https://doi.org/10.1007/s00170-007-1368-2

[16] K. Giasin et al., "Assessment of cutting forces and hole quality in drilling Al2024 aluminium alloy: experimental and finite element study", Int. J. Adv. Manuf. Technol. vol. 87, pp. 2041-2061, 2016, https://doi.org/10.1007/s00170-016-8563-y

[17] R. Sreenivasulu and C.S. Rao, "Optimization of surface roughness, circularity deviation and selection of different aluminium alloys during drilling for automotive and aerospace industry", Ind. J. of Manag. \&Produc. (IJM\&P), vol. 7, no. 2, pp. 413-430, 2016, https://doi.org/110.14807/ijmp.v7i2.414

[18] M. Ramzi et al., "Effect of drilling parameters on quality of the hole", Aust. J. Basic \& Appl. Sci., vol. 11, no. 5, pp. 202-209, 2017, ISSN:1991-8178 EISSN: $2309-8414$

[19] F. F1c1c1, "Evaluation of surface roughness in drilling particle-reinforced composites", $A d v$. Composites Letters, vol. 29, pp. 1-11, 2020, https://doi.org/10.1177/2633366X20937711 